\title{
Cleaning of exhaust gases with low content of sulfur (IV) oxide
}

\author{
Zenovii Znak $^{1}$, Andrii Helesh ${ }^{2}$, Yaroslav Kalymon ${ }^{3}$, Oksana Kurylets ${ }^{4}$, Olha Zin ${ }^{5}$
}

1. Department of Chemistry and Technology of Inorganic Substances, Lviv Polytechnic National University, UKRAINE, Lviv, S. Bandery st., 12, E-mail: znak_zo@ukr.net

2. Department of Chemistry and Technology of Inorganic Substances, Lviv Polytechnic National University, UKRAINE, Lviv, S. Bandery st., 12, E-mail: gelesh75@gmail.com

3. Department of Chemistry and Technology of Inorganic Substances, Lviv Polytechnic National University, UKRAINE, Lviv, S. Bandery st., 12, E-mail: yaroslav.a.kalymon@lpnu.ua

4. KDepartment of Chemistry and Technology of Inorganic Substances, Lviv Polytechnic National University, UKRAINE, Lviv, S. Bandery st., 12, E-mail: kuryletsh@yahoo.com

5. Department of Chemistry and Technology of Inorganic Substances, Lviv Polytechnic National University, UKRAINE, Lviv, S. Bandery st., 12, E-mail: zin.olha@gmail.com

Abstract - The influence of Ferrum (II) sulfate $\left(\mathrm{FeSO}_{4}\right)$ concentration in the absorbent solution and the influence of the process temperature on the efficiency of gas emissions purification in the apparatus with bucket dispersants was investigated.

Keywords - exhaust gases, sulfur (IV) oxide.

\section{Introduction}

Gas emissions of sulfur (IV) oxide $\left(\mathrm{SO}_{2}\right)$ into the atmosphere occupy the second place (after carbon (IV) oxide) by volume and the first place due to harmful effects on the environment. These emissions can lead to crisis environmental conditions, have unpredictable consequences for the health and life of future generations. Therefore, research aimed at developing technologically efficient and cost-effective technologies for the purification of discharged $\mathrm{SO}_{2}$-containing gases is relevant and important.

In the balance of industrial emissions of $\mathrm{SO}_{2}$, the bulk (over $80 \%$ ) accounts for poor exhaust gases (up to $0.5 \% \mathrm{SO}_{2}$ ). Utilizing $\mathrm{SO}_{2}$ from such gases is technologically and technically difficult, economically very costly. Therefore, solving the problem can be achieved by removing $\mathrm{SO}_{2}$ from cheap reagents and waste from other industries. In previous studies, it has been shown that for the purification of gas emissions with low sulfur (IV) oxide it is expedient to use oxidative methods, but as an oxidizer to use air oxygen [1]. The physical and chemical essence of the process corresponds to the greatest extent to the horizontal absorber with bucket dispersants (HABD), which was developed at the department of CTIS [2].

\section{Theoretical part}

The oxidation of $\mathrm{SO}_{2}$ with oxygen in the gas phase is thermodynamically possible under normal conditions. Despite this, gaseous $\mathrm{SO}_{2}$ and $\mathrm{O}_{2}$ do not react directly, since the reaction of $2 \mathrm{SO}_{2}(\mathrm{~g})+\mathrm{O}_{2}(\mathrm{~g}) \rightarrow 2 \mathrm{SO}_{3}(\mathrm{~g})$ is characterized by a high activation energy $(210 \mathrm{~kJ} / \mathrm{mol})$. It can be accelerated by the use of catalysts. Available industrial vanadium catalysts are relatively expensive, with an optimal temperature of at least $410{ }^{\circ} \mathrm{C}$. Therefore, the neutralization of $\mathrm{SO}_{2}$ by its catalytic oxidation in the gas phase is economically inappropriate. Therefore, practical interest is the oxidation of $\mathrm{SO}_{2}$ by oxygen in aqueous, catalytically active solutions. In this aspect, the Ferrum ions are of considerable interest, the source of which may be iron sulfate $\left(\mathrm{FeSO}_{4} \times 7 \mathrm{H}_{2} \mathrm{O}\right)$, which is the withdrawal of many industries.

The reactions that take place can be expressed by the following stoichiometric equations:

$$
\begin{aligned}
& 2 \mathrm{FeSO}_{4}+\mathrm{O}_{2}+\mathrm{SO}_{2} \Leftrightarrow \mathrm{Fe}_{2}\left(\mathrm{SO}_{4}\right)_{3} . \\
& \mathrm{Fe}_{2}\left(\mathrm{SO}_{4}\right)_{3}+\mathrm{SO}_{2}+\mathrm{H}_{2} \mathrm{O} \Leftrightarrow 2 \mathrm{FeSO}_{4}+2 \mathrm{H}_{2} \mathrm{SO}_{4} .
\end{aligned}
$$

In total, this process can be expressed by the following reaction

$$
2 \mathrm{SO}_{2}+\mathrm{O}_{2}+2 \mathrm{H}_{2} \mathrm{O} \Leftrightarrow 2 \mathrm{H}_{2} \mathrm{SO}_{4} \text {. }
$$


These processes are equilibrium, so, changing the conditions, you can direct the process to the desired side. The standard electrode potential of the $\mathrm{Fe}^{3+} \rightarrow \mathrm{Fe}^{2+}$ system is equal to $0.77 \mathrm{~V}$, while the system $\mathrm{O}_{2}+4 \mathrm{H}^{+}+2 \mathrm{e} \rightarrow 2 \mathrm{H}_{2} \mathrm{O}$ equals $1.23 \mathrm{~V}$. Since the electrode potential of the oxidizer is greater than that of the reducing agent, the reaction will take place, and the driving force of the process will be $0.46 \mathrm{~V}$ (1.23-0.77). Consequently, the liquid-phase oxidation of $\mathrm{SO}_{2}$ by oxygen in the presence of $\mathrm{Fe}^{2+} \mathrm{i} \mathrm{Fe}^{3+}$ ions is theoretically possible, characterized by a rather significant driving force.

\section{Experimental part}

Experimental studies were carried out on a laboratory installation of an enlarged type. The installation consisted of three main units: the preparation of a gas mixture for the preparation of the absorbent solution and absorption. As an absorber, HABD was used. Laboratory HABD - is a horizontal cylindrical apparatus (internal diameter 500, length $300 \mathrm{~mm}$ ), made of organic glass. A bucket dispersant was placed on the bottom of the apparatus on a horizontal shaft.

The influence of temperature on the course of the process was studied in the range 35-50 ${ }^{\circ} \mathrm{C}$. The concentration of $\mathrm{FeSO}_{4}$ was changed within the range of $0 \ldots 0.2 \mathrm{~mol} / \mathrm{l}$, and the $\mathrm{SO}_{2}$ content in the gas mixture - within the limits of $3.5 \ldots 19.5 \mathrm{~g} / \mathrm{m}^{3}$.

It was established that the dependences of the absorption and oxidation steps of the absorbed $\mathrm{SO}_{2}$ in the liquid phase on the concentration of Ferrum (II) sulfate have an extreme character with a maximum equal to the concentration of $\mathrm{FeSO}_{4} 0.025 \mathrm{~mol} / \mathrm{l}$. The presence of a maximum can be explained by the fact that the process occurs statically: at first, $\mathrm{Fe}^{2+}$ ions are oxidized to $\mathrm{Fe}^{3+}$, which, in turn, oxidizes chemosorbed $\mathrm{SO}_{2}$ to sulfate ions. Consequently, an increase in the concentration of $\mathrm{Fe}^{2+}$ ions will have a positive effect on the oxidation processes. However, the increase in the concentration of $\mathrm{FeSO}_{4}$ leads to an increase in the acidity of the solution (decrease in $\mathrm{pH}$ ), and this will negatively affect the absorption of $\mathrm{O}_{2}$ and $\mathrm{SO}_{2}$ by the absorbent solution.

An increase in the oxidation rate of sorbed $\mathrm{SO}_{2}$ can be achieved by an increase in temperature, which for this process, obviously, will have some optimal value. This is explained by the fact that, on the one hand, with increasing temperature the solubility of gases decreases, which leads to a decrease in the concentration of their hydrated forms, and, on the other hand, the increase in temperature leads to an increase in the reaction rate $(1,2)$. It is established that the optimum temperature of the process of purifying gases from $\mathrm{SO}_{2}$ by solutions of Ferrum (II) sulfate is in the region of $313 \mathrm{~K}$. In addition, the region of extremum on these dependencies is more pronounced in the case when the contact time in the apparatus is lower. Thus, up to $313 \mathrm{~K}$, the increase in the oxidation rate of sorbed $\mathrm{SO}_{2}$ is greater than the relative reduction in the solubility of gases.

\section{Conclusions}

Studies have helped to identify regularities of $\mathrm{SO}_{2}$ oxidation with oxygen in aqueous solutions of iron sulfates and determine optimal spacing $\mathrm{FeSO}_{4}$ concentration and temperature are respectively equal to $0.015 \ldots 0.03 \mathrm{~mol} / \mathrm{l}$ and $312 \ldots 318 \mathrm{~K}$.

\section{References}

[1] V. Yavorskyi, A. Helesh, I. Yavorskyi, Ya. Kalymon, "A theoretical analysis of chemisorption of sulfur(IV) oxide. Rationale for the choice of an efficient mass-exchange apparatus", no 1/6(79), pp. 32-40, 2016.

[2] V. Yavorskyi, A. Helesh, "Theoretical analysis of efficiency of horizontal apparatus with bucket-like dispersers in the dust trapping system", Chemistry \& chemical technology, no. 9 (4)), pp. 471-478, 2015. 